\title{
A Study of Burial Patterns and Symbolism With Reference to Harappan Sites in India
}

\author{
Satarupa Bal \\ Antiquity and Museums Section, Archaeological Survey of India, New Delhi, India
}

\begin{abstract}
Since time and beyond, when humans first developed the understanding of staying in communities, a sense of affection and adoration grew towards fellow beings. The law of nature of the cycle of life gave rise to the belief in life after death and a sense of intimidation for the same, gave way to supernatural beliefs. Such beliefs gave rise to multifarious customary activities. A study to understand them on the basis of symbolism has paved the way for simplification of the complex rituals, and hence, perceive the prevalent socio-cultural aspects of those times.

Keywords: Burial patterns, Harappa, Harappan burials in India, Burial analysis, Mortuary practices, Pre/Early Harappan Burial, Mature Harappan Burial, Social aspects of Harappan Burials
\end{abstract}

\section{Introduction}

Burial may be defined as "to bury," "grave or tomb," "the act or process of burying," "the act or ceremony of burying” etc., while a burial ground is defined in different terms, such as, burying ground, graveyard, necropolis etc. in the archaeological context. Since the earliest times, the disposal of the dead has been given much importance by the humans. Often, the dead ones were accompanied with food and personal belongings indicating a belief of life after death. The humans attempted to relive the memory of the departed souls and tried to erect a tomb or a memorial stone to remember their close relatives, kith and kin, etc. In the global context, the earliest known burials may be attributed to the Middle Palaeolithic times or Mousterian levels. The presence of burials from the prehistoric context has been found so far from Tabun Cave, Israel, (circa 180,000 years ago). La Ferrassie, Dordogne, France, which provides evidence of remains of eight bodies placed in man-made graves, along with burial goods, protective flagstones, earth mounds, etc. (see http://www.caves.org/grotto/esso/RESOURCES/burials.pdf). The presence of eight adults and two infant skeletal remains from the Middle Palaeolithic context from Shanidar Cave, located in the Zagros Mountains of north eastern Iraq is one of the prominent Neanderthal sites in West Asia (Solecki, 1977, pp. 114-124). The excavations carried out between 1957-1961 have yielded remains of nine Neanderthal skeletons, of which two exhibit clear evidence of performance of burial rituals (Solecki, 1977, p. 114). Two of the nine individuals, from Shanidar IV presented very good evidence of Neanderthal burials dated to 35,000-65,000 years ago. Further, the remains of ancient flower pollens from the soil clinging to the skeletal remains of Shanidar IV presents a very good evidence of attachment and association with the deceased person and as a respect or esteem, the flowers were placed along with the burial. In the Indian context, the evidence for the disposal of

Satarupa Bal, Masters in Archaeology (2 years), University of Calcutta; Post Graduate Diploma in Archaeology (2 years) from Institute of Archaeology, Archaeological Survey of India, Government of India. 
dead in a definite burial mode is noticed from the prehistoric period onwards, most particularly from the Mesolithic period onwards. The Mesolithic sites excavated so far, provide evidences, that can be pieced together to have an understanding of the beliefs and customs of the ancient population towards afterlife and disposal of dead. These systems of internment of the dead ones also help us to understand the multifarious beliefs and customs existed among the various prehistoric communities. The Mesolithic sites that have yielded evidence of burials are widely separated from each other, the sites of the middle Ganga plain is particularly important as they have revealed a large number of burials and a quite deal of multi-disciplinary studies have been conducted on these burials. Sites such as Bhimbetka, Damdama, Sarai Nahar Rai, Mahadaha etc. provide examples of varying burial practices.

\section{Mode of Disposal}

In general sense, burial practice may be defined as "the beliefs and customs associated with the burial of the dead, which was practiced by the cultural inhabitants.” These beliefs, customs, and practices were unique and vary from culture to culture, as it is garnered from the archaeological sources. The past cultural inhabitants not only buried their dead, they also practiced several other modes of disposal of the dead. Two broader modes of disposal noticed from archaeological records were burial and cremation. Burying the dead, in turn had various sub-varieties depending upon the details of the burial contents, position and stature of the skeletal remains, etc. A sub-variety of burying the dead is also observed from archaeological evidence. It is a symbolic burial. The symbolic burials often contain no remains of human remains and a ritual only is performed with all the paraphernalia of a usual inhumation burial. The reason for such a burial may be varied. Often the body remains of a person are not found, and hence, a symbolic burial commemorating that person is performed. Otherwise, if the culture is in a warring society and if the person concerned dies in a war or conflict, whatever remains of the person could be gathered are collected and assembled together and a burial ritual is performed. Cremation of dead was also a major kind of disposal of dead during ancient times. Although evidences are rare, enough evidences from literary sources are found for cremating the dead ones. In certain cases, the ashes and charred remains after the cremation of dead were also placed in urns and the usual burial rituals were performed. Cremation is a common practice of disposal of the dead among many sects of the society during the modern times. The cremation of the deceased person also involved in a series of rituals which might have evolved through the passage of time and crystallized after trial and error. The basic function of performing such a ritual may be deduced as highly philosophical and metaphysical. It is the yearning of the close kin of the deceased person to ensure a life of peace after his death in the nether world. In other words, it is a belief of life after death. It is also the differentiation of body and soul, and the departure of the soul from the earthly body. The belief conjures a life for this soul after it leaves the earthly body. The burial rituals are also an outcome of resting this soul of the departed person in peace. Due to the belief, that if the soul is not rested in peace, it might also torment or wander in a restless state of motion. The customary burial practices ensure a set of rituals performed at the time of internment of the body with a belief that the soul rests in peace and his/her afterlife is secured. It is with this belief system that several ancient civilizations devised various sets of burial practices. It also depended upon the social status of the person which was proportionately reflected in the nature of the burial goods. The internment of a body in the burial has also its significance. Based upon the position of the body, various definitions are given. Thus, in an extended burial, the body is placed lying flat with arms and legs straight, or with the arms folded on the chest. The extended burials may be supine (lying on the back) or prone 
(lying on the front). The other modes are flexed, in which the legs of the body are bend, and crouched, where the legs of a body is folded up to the chest. The flexed posture may also be supine, or turned towards one side, either to the right or left of the dead body. In the burial record of different cultures and civilizations, several such postures of internment of the human bodies could be noticed. The archaeological evidence also indicates the presence of single, double, or several dead bodies in a single grave pit. The evidence from Lothal of a burial consisting of two skeletons has been interpreted as a Sati type burial. Multiple burials are also found, as gleaned from the Lothal evidence. Examples of human burials in association with animal remains are also found from the archaeological records, which indicate specialized ritualistic practices among the ancient cultures.

The above discussion may indicate that not only do the Symbolic burials provide example of factors of symbolism, but the other modes of disposal of dead, mentioned here, bring forth aspects of a typical pattern or symbolism followed in interring the dead focusing on belief in afterlife. With this view in mind few pre early Harappan and Harappan sites would be studied and the usual pattern followed in these sites would be studied to bring out an aspect of symbolism.

\section{Example of a Few Sites in the Pre-Early Harappan Period}

\section{Santhli}

The settlement at Santhli is locally known as "Gachi-na-thumdo" and is designated as Santhli II by the excavators of M.S. University, Baroda (Ingenjörsfirman Anders Rundgren [IAR], 1993-1994, p. 25). It is located in the district Banaskantha of Gujarat. The excavation brought to light a habitation deposit of nearly 40 cm, which is sub-divided into two cultural occupations, viz. Period I (Mesolithic) and Period II (Chalcolithic II) (IAR 1993-1994, p. 25-27). Period I is represented by the presence of both geometric and non-geometric microliths (IAR 1993-1994, p. 25). The Period II (Chalcolithic settlement) is on the other hand, marked by the presence of two extended inhumation burials, with east-west orientation and the head on the east (IAR 1993-1994, p. 27).

The first burial is an example of a joint (double) burial. Two adult individuals have been laid in a supine position with their heads facing each other. These two individuals have been interred in a single pit and the associated grave furniture consist of five pottery vessels comparable to that of Nagwada and placed in the pre-early Harappan context (IAR 1993-1994, p. 27). Burial 2 is that of a child burial, found in association with pottery vessels consisting of beaker, shallow bowl, or dish, which is similar to that found from Burial 1 . The burials are devoid of any other grave goods. Some sites were reported to represent only burial pottery similar to Santhli, but devoid of any cultural material (Hegde et al., 1988).

\section{Nagwada}

Nagwada is located at a distance of $3 \mathrm{~km}$ south of the village Nagwada. It consists of four different habitational areas with assemblages ranging from Anarta, Amri-Nal, Harappan, and Lustrous Red Ware (Hegde et al., 1988, p. 58).

Only Period IA is represented by the presence of burials. The burials include extended inhumations and pot burials. The extended burials are in east-west orientation with the burial furniture placed near the foot. The pot burials consisted of symbolic representation of internment of only burial pottery and are devoid of skeletal remains. They are found in an east-west orientation. The burial pottery is varied in all the burials. One of the burials has ten complete pots, while the second contains only six. The third one is represented by only a large 
jar with a lid cover (Hegde et al., 1988, p.58). The burial pottery consists of shapes like dish-on-stand, dish without carination, beaker, bowl, disc-based globular jar, and short-necked globular vessel (Hegde et al., 1988, p.58). The ceramics are similar to those found from the upper pre-Harappan levels at Amri, Nal, and Kot Diji.

\section{Example of a Few Sites in the Mature Harappan Period}

\section{Dholavira}

Dholavira is located in the district Kachchh, Gujarat (Bisht, 1989-1990). The excavation carried out by R.S. Bisht starting from 1989-1990 to 2004-2005, revealed a continuous occupation of 1,500 years starting around circa 3,000 BC up to 1,500 BC marked by seven cultural stages (Bisht, 2008).

The funerary remains at Dholavira has been traced on the east, west, and north of the fortified settlement, however, the ones belonging to the Harappan period is concentrated to the west consist of various types of funerary architecture, spreading over an area of roughly about 50 ha (Bisht, 2008). Fifteen sepulchral remains were investigated, which were found to be akin to other Harappan burials in terms of orientation (i.e., north-south). The burials were predominantly memorial in nature as no skeletal remains were unearthed except two inhumation and few fractional burials. The burials were found interred with varying artifacts, such as pottery, beads, gold etc. One of the burial, named as Tumulus I is exceptionally rich in burial goods containing a complete steatite circular beaded necklace, gold bangle, and pottery. The burials have been placed in the Stages III, IV, and V on the basis of typology and other aspects. Only one burial has been dated to Stage VI. Another burial of Stage VII was exposed on the surface in the citadel mound. In addition to above, two graves were also unearthed within the fortification limits in the lower town. The following types (Bisht, 2008) have been identified at Dholavira, based on the funerary architecture: Rectangular Memorial (Built memorial, Cist or cist in cairn, Rock-cut); Cairn (round, oval, long oval, or egg-shaped); Composite graves in a circle, a semicircle, or a rectangle; Fractional burial; Inhumation; and Hemispherical monument or tumulus. The general pattern noticed in the burials is the usual trend of north-south orientation, with rare deviation sometimes.

\section{Rakhigarhi}

Rakhigarhi is the largest Harappan site in the Indian subcontinent and is located in the district Hissar of Haryana. The excavations brought to light the early Harappan habitation in RGR 6 has been sub-divided into pre-formative urbanism (Period I a) and formative urbanism (Period I b) (IAR, 1999-2000, p. 30). The ceramic industry of Rakhigarhi yielded the six fabrics of Kalibangan, grooved ware of Hakra origin with regional variation and typical Rakhigarhi Chocolate slipped ware.

The funerary remains at Rakhigarhi can be found nearly $200 \mathrm{~m}$ to the north of RGR 1, 2, and 3 mounds, revealing a total of eleven burials (IAR, 1999-2000, p. 34). The burials belong to the primary inhumation type extended burials wherein the dead ones were interred in an oblong pit in north-south orientation with the head turned towards the east (IAR, 1999-2000, p. 34). Three phases of burial activity in terms of internment have been noticed with Burial 11, which is the earliest among them while the last phase burials are damaged. The grave goods consist generally of vases, bowls, pans, dish-on-stand, etc., placed near the head while three burials have shell bangles in their left hand and a miniature gold armlet found in one case (IAR, 1999-2000, p. 34).

\section{Kalibangan}

Kalibangan, meaning "black bangles" in local dialect, is located on the left bank of River Ghaggar (generally identified with ancient River Sarasvati) in district Hanumangarh in Rajasthan. The chronology of the 
Early Harappans at Kalibangan has been estimated between 3,000 and 2,700 BCE (Lal, Jagat, \& Madhu, 2003) The Period II at Kalibangan is represented by the arrival of Mature Harappans, which saw a major transformation in the overall plan and layout of the city. The city is represented by two distinct divisions, named here as citadel (KLB 1) which occupied the already existing Early Harappan habitation and the lower town, an extensive mound towards the east.

The cemetery area, which is located nearly 300 m west-southwest of the habitation area at Kalibangan, is at present very close to the flood plain of River Ghaggar. The excavation brought to light three types of burials as mentioned below (Thapar, 1975):

1. Extended inhumation in rectangular or oval pit;

2. Pot-burial in a circular pit;

3. Rectangular or oval grave-pit containing only pottery and other funerary objects.

The characteristic feature of the cemetery area at Kalibangan is that separate areas were demarcated for different burial types, and the area was divided into two prominent ones, one each for the extended inhumation and other for pot burial types (Sharma, 2007). Further, it was also noticed that within the demarcated areas are sub-areas in the extended inhumation type, which might have been meant for family groups (Sharma, 2007).

\section{Lothal}

Lothal is situated near the village Saragwala of Ahmedabad district in Gujarat. Lothal in Gujarati means "the mound of the dead" (Rao, 1979, p. 18). The site was discovered by S. R. Rao in 1954. Lothal is located between two rivers namely, Bhogava and Sabarmati (Rao, 1979, p. 19). Prof. Rao gives the following cultural periods, structural phases and their sub-phases at Lothal based on the excavations (Rao, 1979, p. 24): Period B-Late Harappan; Period A-Mature Harappan.

The cemetery at Lothal was located on the western edge of the mound (Rao, 1979, p. 68). The majority of the burials belonged to the Mature Harappan phase. The burials here found were assigned to the Phases III, IV, and V based on the stratigraphy and associated cultural materials from the habitation area (Rao, 1979, p. 69). The excavation brought to light a total of 21 graves belonging to three structural phases. Out of these 20 graves, in sixteen graves the pit lines could be clearly made out, while in the remaining four the pit lines were not clear and it contained fragmentary bones and potsherds (Rao, 1979, p. 137). Lothal is also famous for the double burials it has yielded. Of the 16 burials, 13 contained single skeletons each while three contained double burials. The orientation of the burials is in a north-south direction, with the head towards the north, slightly raised and tilted towards the east, while the legs and hands are pressed (Rao, 1979, p. 69). The most common burial practice noticed at Lothal is that of extended burial while no substantial evidence for fractional burials was encountered (Rao, 1979, p. 140). The arms are found pressed on each other, while the body was laid down in supine position. In some cases, the hands were placed on the side. In the case of legs, they were found placed in a slightly flexed condition sideways and placed apart, while the feet were touching each other (Rao, 1979, pp. 140-141). The important contribution from Lothal can be said to be the evidence of joint burials, of which three such instances were excavated. The Grave 7 yielded a joint burial, which is also lined with mud bricks, contains a joint burial of two adult male individuals with "familial resemblance" between them (Rao, 1979, p. 140). It was also observed that before laying the dead body in the burial pit, some sort of ritual was performed by putting a thin layer of kankar on the floor of the burial pit, and then the funerary vessels and skeleton were deposited (Rao, 1979, p. 69). After the placement of dead body along with the burial goods, the grave pit was 
again filled with kankar and then by earth. In some cases, the piled up earth rose above the ground level. Normally, all the graves were without any lining inside the grave pit, with only one exception in which mud-bricks were used for lining inside the grave pit (Rao, 1979, p. 140). Apart from the pottery finds, the burials were also interred with ornaments such as copper ring and shell bangles.

\section{Farmana}

Farmana, locally known as Daksh Kheda, is located near the villages of Farmana, Seman and Bhaini Chandrapal, $45 \mathrm{~km}$ from the district Rohtak, Haryana. The excavations at Farmana (Shinde, Osada, \& Kumar 2011, pp. 38-39) have brought to light the following cultural sequence: Period I Early Harappan (regional Hakra Culture Traditions (3,500-2,600 BC); and Period II Mature Harappan (sub-divided into three phases of occupations).

The cemetery site at Farmana is located nearly $900 \mathrm{~m}$ to the northwest of the habitation mound, which was also accidentally discovered in 2007-2008 when the local farmers were removing a large portion of soil with mechanised means (Shinde, Osada, \& Kumar, 2011, p. 23). The extent of the cemetery site at Farmana has been estimated to around 3 ha and had survived more or less fully, which has led the excavators to plan a large-scale excavation to expose them. The location of the cemetery complex to the west of the habitational remains more or less confirms to the general practice of the Harappan settlements. The investigations revealed that the burials pits were dug into the natural alluvium mostly brownish/yellowish in color and the pit refill soil later turned into greyish/blackish in color, which facilitated the easy identification of each burial pit location (Shinde, Osada, \& Kumar, 2011, p. 534). A total of 70 burials were excavated at the site. Different orientations of internment of skeletal remains and burial goods have been noticed. The orientations noticed among the burials are northwest-southeast, north-south and northeast-southwest. The excavators have also identified three distinct phases of Harappan culture and chronological sequence in the burials based on the pottery and burial goods interned ranging from more of Kot Diji variety pots in the early period, followed by gradually diminishing number of this variety in the succeeding phase and prevalence of typical Harappan pottery in the last phase.

The burials found at Farmana have been categorized on the basis of skeletal and burial goods (Shinde, Osada, \& Kumar, 2011, p. 534), namely, primary burials, secondary burials, and symbolic burials.

All the burials are found in a burial pit, rectangular in shape with their sides cut perfectly vertical and bottoms flat (Shinde, Osada, \& Kumar, 2011, p. 534). The typical Harappan pottery types found from the burials are pots, jars, bowls, beakers, dishes, dish-on-stands, bowl-on-stands, pot-on-stands, and stands. The typical non- Harappan pottery types are pots, jars, bowls, beakers, dishes, dish-on-stands, pedestalled bowls, pot-on-stands, and lids. The burials of Phase I are distinguished by the absence of non-Harappan pottery and characterized by recognizable Harappan pottery types like pots, beakers, dish-on-stand and bowl-on-stand. Phase II burials are characterized by the continuation of Harappan pottery types, with the inclusion of non-Harappan pottery types. The same types, along with a few incorporation of slender type continue in the next two phases (Shinde, Osada, \& Kumar, 2011, p. 713).

\section{Discussion}

Usually, the most significant aspect of the burial gamut of the Harappan sites in India is that, the Harappan burials are found away from the settlement, either on the west or south west of the settlements. For example, at Dholavira, the burial area is nearly $200 \mathrm{~m}$ west of the settlement area. This is very much distinguishable from the Chalcolithic burials of the Central India and Deccan, where the burials are found below the floors of houses. 
The burials from the Harappan sites may be broadly classified into inhumation or primary and non-inhumation or secondary burials. Normally, the Harappans burials are found in a north-south orientation, although some exceptions are found as at Rupnagar, where the orientation is northwest-southeast. The examples from Kalibangan and Lothal have mud-bricks lined all around the burials, while only one burial at Sanauli yielded evidence of mud-brick lining. The burials from Dholavira is an exception in the sense that here, some of the burials were found lined with limestone slabs all around, and even capped with a huge limestone slab to mark the grave. These burials from Dholavira often remind of the types we commonly encounter from the megalithic cist graves. The burials of the Harappan sites were either placed in a north-south or northwest-southwest orientation. The burials may be a primary one, one with complete skeletal remains of the dead person, or a secondary one, without any skeletal remains, or in some instances scattered bones. This may be due to several reasons, disturbances in the past due to repeated use of the cemetery area, or disturbances caused due to removal of valuable things, as in grave plundering. The burials may also be symbolic ones, like the ones encountered at Sanauli, which neither contain complete nor fragmentary skeletal remains. These symbolic burials contain a mere representation of a human torso, which at times contain personal belongings of the dead person. The burials were often found with either elaborate or simple burial goods, in the form of various kinds of pottery, personal belongings of the dead person. The burial pottery was also arranged in such a way that certain pots were placed at the northern portion of the burial pit, well beyond the head of the dead person, and also certain pots were placed right at the centre of the burial pit. The evidence also indicates that the dead body was actually placed above these burial pots, which were placed at the central portion of the burial pit. The placing of the dead body inside the burial pit also varies from site to site and also at times within a site itself. The dead person was normally laid down in supine position. However, at times evidence for flexed, crouched, position is also noticed. At times the dead body was also placed with the head faced towards the east, while in certain cases the head is placed in a raised position in comparison to the body. The hand and leg position of the dead body also varies as noticed from various examples. In some cases, the hands are folded and kept over the hip, while some female burials had their hands kept cross-holding, with one hand crossing body and holding the other hand.

Such practices of laying the bodies in supine or flexed position may be due to the comfort provided by the fellow kins to the dead person in his journey towards the other world in afterlife. The crouched position may indicate a representation of the dead being laid down in the position of a new born child in the womb of a mother. This may have been done to return the human being to the heavenly abode in the same position as he/she had been born into this world. The practice of turning the head towards the east may be due to the practice of facing the dead towards the source of life and light on earth - the sun, so that the sacred light of the sun directs the dead to his/her heavenly abode. The raised position of the head as compared to the rest of the body as seen in a few Harappan sites may be a representation of cushion or comfortable rest under the head, symbolizing a peaceful journey to the heaven. The position of the hands beside or across the body too might symbolize a graceful stature for the females, which are represented in that way in the burial repertoire. Ornaments also symbolize the status or tastes of the dead buried along with them and also signify the material resources of the catchment area of the particular sites. Hence, the aspect of symbolism may be intricately looked into to derive a pattern in the burial practices of the Harappans.

As conclusion, it may be said that looking at the extensive and vast population of the Harappan sites vis-à-vis the number of burials actually encountered, it can be noticed that the evidence of disposal of dead 
through burying may be only fractional. Hence, it may be presumable that apart from burying the dead, a section of the Harappan population also followed other kinds of disposal, for example, cremation. Evidence for cremating the dead has also been found from the excavation of Harappan sites, for example, at Tarkhanwala Dhera, a Mature Harappan site in Rajasthan. The inference for cremation is also found from other sites like Mohenjo-daro, Chanhu-daro, Harappa and Baluchistan sites from the post cremation urns. Hence population belonging to different beliefs, may be religious or other social implications, might have contemporarily coexisted during the same period and over wide span of regions. A pattern of symbolism can hence be derived in such studies as mentioned above.

\section{References}

Bisht, R. S. (1989-1990). Dholavira: New horizons of Indus civilization. Puratattva, 20, 71.

Bisht, R. S. (2008). Dholavira Excavations: 1990-94, in Facets of Indian Civilization, Recent Perspectives (Essay in Honour of Prof. B.B. Lal) (vol. I) (Chiefed.) Soo. J.P. Joshi.

Bisht, R. S. (2011). How Harappans honoured death at Dholavira. Proceedings of Conference held at L.M.U, L.A, USA.

Hegde, K. T. M., Sonawane, V. H., Shah, D. R., Bhan, K. K., Ajitprasad, K. K., \& Chandran, S. P. (1988). Excavation at Nagwada in 1986 and 1987: A preliminary report. Man and Environment, XII, 55.

Indian Archaeology: A Review (IAR). (1999-2000). The Archaeological Survey of India, New Delhi. Retrieved from http://www.asi.nic.in/nmma_reviews/Indian\%20Archaeology\%201999-2000\%20A\%20Review.pdf

Indian Archaeology: A Review. (1993-1994). The Archaeological Survey of India, New Delhi.

Lal, B. B., Jagat, B. K., \& Thapar, M. B. (2003). Excavations at Kalibangan: The early Harappans (1960-1969). Memoirs of the Archaeological Survey of India, 98, 25-26.

Rao, S. R. (1979). Lothal A Harappan Port Town (1955-62). Memoirs of the Archaeological Survey of India, I(78), 18-141.

Sharma, A. K. (2007). The cemetery. In B. B. Lal (Eds.), Excavations at Kalibangan: The Harappans (1960-1969) Part III (p. 1187). Delhi: Archaeological Survey of India.

Shinde, V., Osada, T., \& Kumar, M. (2011). Excavations at Farmana, district Rohtak, Haryana, India, 2006-2008. Kyoto, Japan: Research Institute for Humanity and Nature.

Solecki, R. S. (1977). The implications of the Shanidar Cave Neanderthal flower burial. Annals of the New York Academy of Sciences, 293(1), 114-124.

Thapar, B. K. (1975). Kalibangan: A Harappan metropolis beyond the Indus Valley. Expedition, 17(2), 31. 